\title{
Gel-Loading Tip Vitrification of In Vitro- Matured Bovine Oocytes and Subsequent Embryo Production by IVF and Nuclear Transfer
}

\author{
Keiichiro Tominaga ${ }^{1 *}$, Yukako Hamada ${ }^{1}$ and Shinichi Hochi ${ }^{2}$ \\ ${ }^{1}$ Hyogo Prefectural Institute for Agriculture, Forestry and Fisheries, 1533 Minamino-oka, Befu, \\ Kasai, Hyogo 679-0198, Japan \\ ${ }^{2}$ Faculty of Textile Science and Technology, Shinshu University, 3-15-1 Tokida, Ueda, Nagano \\ 386-8567, Japan
}

\begin{abstract}
The purpose of this study was to cryopreserve bovine oocytes for subsequent blastocyst production by in vitro fertilization (IVF) and somatic cell nuclear transfer (SCNT). A vitrification procedure using gel-loading tips as containers was applied to cryopreserve in vitro-matured and denuded oocytes. In Experiment 1, oocytes were vitrified-warmed in vitrification solution (VS) containing $25,28,31$, or $40 \%$ ethylene glycol (EG) and $1.0 \mathrm{M}$ sucrose. The proportions of survived oocytes that appeared to be morphologically normal after warming, and cleaved oocytes after IVF were lower with 25\% EG-based VS when compared with 28-40\% EG-based VS. Blastocyst yields 8 days after IVF of oocytes vitrified-warmed in 28 and $31 \%$ EG-based VS (12 and 17\%, respectively) were not significantly different from those of the fresh control group (32\%). Day-7 blastocysts derived from vitrified oocytes were composed of a smaller number of inner cell mass (ICM) and trophectoderm cells than the fresh Day-7 blastocysts. In Experiment 2, oocytes vitrifiedwarmed in $31 \%$ EG-based VS were subjected to enucleation and SCNT. The proportions of oocytes fused and cleaved in the vitrified group were comparable to those in the fresh control group. Blastocyst yields 6 and 7 days after SCNT of vitrified oocytes were lower than those of control oocytes, but 8 days after the SCNT, the difference became statistically comparable (45 versus $58 \%$ in control group). ICM and trophectoderm cell numbers in Day-7 blastocysts derived from vitrified oocytes were smaller than those of control blastocysts
\end{abstract}

Received: May 17, 2005

Accepted: July 20, 2005

*To whom correspondence should be addressed.

e-mail:ktomi-@nike.eonet.ne.jp due to a slower developmental rate. In conclusion, bovine oocytes cryopreserved by vitrification in gelloading tip were capable of developing into blastocysts after conventional IVF and SCNT, with slightly smaller cell numbers and a slower developmental rate.

Key words: Bovine oocytes, Gel-loading tip, Nuclear transfer, Vitrification

\section{Introduction}

The survival rate of cryopreserved bovine oocytes and subsequent developmental potential is low, as only a few pregnancies or calves have been produced [1-3]. During the last decade, a novel vitrification procedure characterized by an ultra-rapid cooling rate became promising for successful cryopreservation of bovine oocytes, since Martino et al. [4] first reported that bovine cumulus-oocyte complexes (COCs) survived vitrification and warming using electron microscope grids. An ultrarapid cooling rate has been achieved with cryodevices such as open-pulled straws (OPS) [5, 6], cryoloop [7] and cryotop $[8,9]$, or without using any devices (the micro-droplet method [10] and solid-surface vitrification method [11]). Several modifications of the devices include the use of glass-pulled capillaries [12] and nylon mesh [13]. We have developed an improved OPS system using commercially available gel-loading tips for cryopreserving in vitro-produced bovine embryos at various developmental stages $[14,15]$. In most cases $[5-9,14,15]$, the vitrification solution (VS) contains a permeable mixture of ethylene glycol (EG) and dimethyl sulfoxide (DMSO) at a total concentration of $30-40 \%$, 
and non-permeable sucrose at 0.5-1.0 M. In contrast, Papis et al. [10] reported a high developmental rate into blastocysts of in vitro-matured bovine oocytes after micro-droplet vitrification in VS containing 31\% EG +1.0 $\mathrm{M}$ sucrose and in vitro fertilization (IVF). Dinnyes et al. [11] reported a high yield of bovine blastocysts from in vitro-matured oocytes after solid-surface vitrification in VS containing $35 \%$ EG $+5 \%$ polyvinylpyrrolidone (PVP) $+0.4 \mathrm{M}$ trehalose and subsequent somatic cell nuclear transfer (SCNT), comparable to the yield from fresh control oocytes.

The present study was undertaken to extend the utility of gel-loading tip vitrification to in vitro-matured bovine oocytes. Following the determination of the optimal concentration of EG in VS under a conventional IVF system, the quality of blastocysts produced by IVF and SCNT of post-warm oocytes was evaluated from the developmental kinetics and the total/inner cell mass (ICM) cell number.

\section{Materials and Methods}

\section{Preparation of oocytes}

Bovine COCs were matured in vitro as described previously [16]. Briefly, abattoir-derived ovaries from Holstein, Japanese Black, and crossbred cows and heifers were transported to the laboratory in Ringer's solution at $30-37^{\circ} \mathrm{C}$ within $2 \mathrm{~h}$ of slaughter. The COCs were aspirated from follicles $2-5 \mathrm{~mm}$ in diameter and cultured in TCM199 medium (Gibco BRL, Grand Island, NY, USA) supplemented with $5 \%(\mathrm{v} / \mathrm{v})$ fetal calf serum (FCS; Cansera International Inc., Etobicoke, ON, Canada), $0.002 \mathrm{AU} / \mathrm{mL} \mathrm{FSH}$ (Antrin; Denka Pharmaceutical Co., Ltd., Kawasaki, Japan), and $1 \mu \mathrm{g} /$ $\mathrm{mL}$ estradiol-17 $\beta$ (Sigma Chemical Co., St. Louis, MO, USA) for 19-20 h (Experiment 1) or 18-19 h (Experiment 2) at $38.5^{\circ} \mathrm{C}$ in $5 \% \mathrm{CO}_{2}$ in air, with a density of $30-40$ COCs per $750 \mu \mathrm{L}$ of the IVM medium. The oocytes were freed from cumulus cells by vortex mixing (IVF) or pipetting (SCNT) in $\mathrm{Ca}^{2+}$ and $\mathrm{Mg}^{2+}$-free Dulbecco's phosphate buffered saline (D-PBS; Nissui Pharmaceutical Co., Ltd., Tokyo, Japan) containing $0.025 \%$ hyaluronidase (Sigma).

\section{Vitrification and warming}

Oocytes were cryopreserved by vitrification using gelloading tips as containers, according to the method of Tominaga and Hamada [14] with some modifications. Briefly, 5-7 oocytes with an extruding first polar body were exposed to $3 \%$ EG in TCM199 +20\% FCS for $10-$ 15 min (Expereiment 1) or 8-12 min (Experiment 2) at $37^{\circ} \mathrm{C}$. The oocytes were then equilibrated to a VS composed of $25,28,31$, or $40 \% E G+1.0 \mathrm{M}$ sucrose in TCM199 $+20 \%$ FCS for $30 \mathrm{sec}$ at $37^{\circ} \mathrm{C}$, and then were aspirated with $0.6 \mu \mathrm{L}$ VS into a gel-loading tip (NK-tip; NK System, Osaka, Japan) equipped with a $0.1 / 10-\mu \mathrm{L}$ micropipette (Eppendorf, Hamburg, Germany). After being plunged into liquid nitrogen, the gel-loading tips were set in holding $0.5 \mathrm{~mL}$ plastic straws (IMV, L'Aigle, France) and stored for at least 1 day. Oocytes were warmed by immersing the tip part of the gel-loading tip into TCM $199+20 \%$ FCS at $37^{\circ} \mathrm{C}$, and were expelled from the gel-loading tip and held for $3 \mathrm{~min}$. The oocytes were then washed twice with the fresh TCM199 +20\% FCS at 5 min intervals, and were cultured in the IVM medium at $38.5^{\circ} \mathrm{C}$ in $5 \% \mathrm{CO}_{2}$ in air for $2-3 \mathrm{~h}$ prior to IVF and for $1 \mathrm{~h}$ prior to SCNT.

\section{IVF}

A frozen-thawed sperm suspension $\left(1 \times 10^{7}\right.$ sperm/ $\mathrm{mL}$ ) was prepared in Brackett and Oliphant (BO) medium [17] supplemented with $20 \mathrm{mg} / \mathrm{mL}$ BSA (Sigma) and $20 \mu \mathrm{g} / \mathrm{mL}$ heparin (Novo-Heparin 100; Novo Industry A/S, Osaka, Japan) after being washed with a discontinuous gradient of 90/45\% Percoll (Pharmacia, Uppsala, Sweden) in BSA-free BO medium supplemented with $5 \mathrm{mM}$ theophylline (Sigma) for $5 \mathrm{~min}$ at $500 \times \mathrm{g}$. For IVF, a $50-\mu \mathrm{L}$ sperm suspension was added to 20 oocytes in a $50-\mu \mathrm{L}$ microdrop of the $\mathrm{BO} /$ $\mathrm{BSA} / \mathrm{heparin}$ medium under mineral oil (Nacalai Tesque, Inc., Kyoto, Japan). Starting $6 \mathrm{~h}$ after IVF, the presumptive zygotes were cultured for 3 days in CR1aa medium [18], supplemented with $3 \mathrm{mg} / \mathrm{mL}$ fatty acidfree BSA (Sigma) and $0.25 \mathrm{mg} / \mathrm{mL}$ linoleic acid-albumin (LAA; Sigma), and for 2 days in CR1aa medium supplemented with $5 \% \mathrm{FCS}$ in a 4 -well multidish at $38.5^{\circ} \mathrm{C}$ in $5 \% \mathrm{CO}_{2}, 5 \% \mathrm{O}_{2}$, and $90 \% \mathrm{~N}_{2}$ (15 to 20 zygotes per $750 \mu \mathrm{L}$ medium). Embryos were cultured for an additional 3 days in TCM $199+20 \%$ FCS supplemented with $0.1 \mathrm{mM} \beta$-mercaptoethanol (Sigma) at $38.5^{\circ} \mathrm{C}$ in $5 \% \mathrm{CO}_{2}$ in air.

\section{SCNT}

The SCNT was performed according to the method of Akagi et al. [19] with minor modifications. Briefly, oocytes were enucleated by piercing the zona pellucida with a glass needle and squeezing out the polar body and a small volume of cytoplasm lying beneath the polar body. Successful enucleation of each oocyte was confirmed by Hoechst 33342 (Sigma) fluorescent staining of the corresponding karyoplast that was squeezed out. At passage 12-17, 80 percent confluent 
cumulus oophorus cells were individually inserted into the perivitelline space of the cytoplasts. The donor cellcytoplast couplets were fused in Zimmermann cell fusion medium using a direct current pulse $(25 \mathrm{~V} / \mathrm{mm}$, $25 \mu \mathrm{sec})$ generated by a BTX200 Electro Cell Manipulator (BTX, San Diego, CA) with needle-type electrodes. Fifteen minutes after the electrofusion treatment, the fused oocytes were activated by a combined treatment of direct current pulse $(20 \mathrm{~V} / \mathrm{mm}$, $20 \mu \mathrm{sec}$ ) in a 1-mm gap electrofusion chamber and 10 $\mu \mathrm{g} / \mathrm{mL}$ cycloheximide (Sigma) and $0.3 \%$ BSA in CR1aa medium in $5 \% \mathrm{CO}_{2}, 5 \% \mathrm{O}_{2}$, and $90 \% \mathrm{~N}_{2}$ at $38.5^{\circ} \mathrm{C}$ for 5 h. The reconstructed embryos were cultured for up to 8 days, as described above for culturing the IVF-derived embryos.

\section{Immunosurgery and differential staining}

The number of ICM and trophectoderm cells of Day-7 blastocysts was determined by a differential cell staining technique, as described previously [14], allowing determination of the total number of cells for blastocysts and the percentage of ICM cells based on the total number of blastocyst cells. Briefly, blastocysts were treated with $0.5 \%$ pronase (Pronase E, Sigma) in DPBS for 5 to $10 \mathrm{~min}$ and zona-free embryos were incubated for $10 \mathrm{~min}$ in $10 \mathrm{mM}$ trinitrobenzene sulphonic acid (Nacalai) in $\mathrm{Ca}^{2+}$ and $\mathrm{Mg}^{2+}$-free D-PBS containing 4 $\mathrm{mg} / \mathrm{mL}$ PVP (Sigma) on an ice plate. The embryos were then incubated for $30 \mathrm{~min}$ in TCM199 containing $0.1 \mathrm{mg} / \mathrm{mL}$ anti-dinitrophenol BSA (ICN Biomedicals, Inc., Aurora, $\mathrm{OH}, \mathrm{USA}$ ) and for a subsequent $20 \mathrm{~min}$ in TCM199 containing $20 \%$ guinea pig complement (Rockland Immunochemicals, Inc., Gilbertsville, PA, USA), $10 \mu \mathrm{g} / \mathrm{mL}$ propidium iodide (Sigma), and $10 \mu \mathrm{g} /$ $\mathrm{mL}$ Hoechst 33342 at $38.5^{\circ} \mathrm{C}$. Finally, embryos were washed twice in D-PBS, mounted on a glass slide with a mounting reagent (Mounting medium: Kirkegaard \& Perry Laboratories, Inc., Gaithersburg, MD, USA), and examined at $\times 100$ magnification under a fluorescence microscope at $330-380 \mathrm{~nm}$.

\section{Experimental design}

In Experiment 1, the optimum concentration of EG for VS supplemented with 1.0 M sucrose was examined. Oocytes were vitrified-warmed in a VS of $25,28,31$, or $40 \% \mathrm{EG}$ and $1.0 \mathrm{M}$ sucrose. The post-warm oocytes were subjected to conventional IVF and in vitro culture for 8 days. Blastocysts harvested on Day-7 (Day-0 was defined as the day of IVF) were subjected to differential cell staining. In Experiment 2, the utility of post-warm oocytes for embryo production by SCNT was examined.
Oocytes were vitrified-warmed in a VS of $31 \% \mathrm{EG}$ and $1.0 \mathrm{M}$ sucrose. The post-warm oocytes were enucleated and subjected to SCNT. Day-7 blastocysts (Day- 0 was defined as the day of cell fusion) were also subjected to the differential cell staining.

\section{Statistical analysis}

The experiments were repeated at least four times. The percentage data for each replicate were arc-sinetransformed before being subjected to one-way ANOVA. Data were compared using the Tukey's test. $A$ value of $P<0.05$ was chosen as an indication of statistical significance.

\section{Results}

\section{Experiment 1}

When oocytes were vitrified-warmed in VS containing $25,28,31$, or $40 \% E G$ and $1.0 \mathrm{M}$ sucrose, the proportions of surviving oocytes that appeared morphologically normal after warming and the cleaved oocytes after IVF were lower with 25\% EG-based VS than with $28-40 \%$ EG-based VS (Fig. 1, Table 1). Blastocyst yields 8 days after IVF of oocytes vitrifiedwarmed in 25 and $40 \%$ EG-based VS ( 8 and $10 \%$, respectively) were significantly different from the yield of the fresh control group (32\%), while the yield for 28 and $31 \%$ EG-based VS (12 and 17\%, respectively) were intermediate and not significantly different from others. Day-7 blastocysts derived from vitrified oocytes (Fig. 2) were composed of a smaller number of ICM and trophectoderm cells than the fresh Day-7 blastocysts, but the percentages of ICM cells based on the total number of blastocyst cells were comparable among the groups (Table 1).

\section{Experiment 2}

Oocytes that were the morphologically normal (95\%, 99/104) after warming were subjected to enucleation, resulting in a successful enucleation rate of $88 \%$ (87/ 99). This proportion was similar to that for fresh control oocytes $(93 \%, 90 / 97)$. The proportions of oocytes fused and cleaved in the vitrified group were comparable to those in the fresh control groups (Table 2). The blastocyst yields 6 and 7 days after SCNT of vitrified oocytes were lower than those of control oocytes, but 8 days after the SCNT the difference became statistically comparable (45 vs. $58 \%$ in control group). The numbers of ICM and trophectoderm cells in Day-7 blastocysts derived from vitrified oocytes were smaller than those of control blastocysts, but there was no 

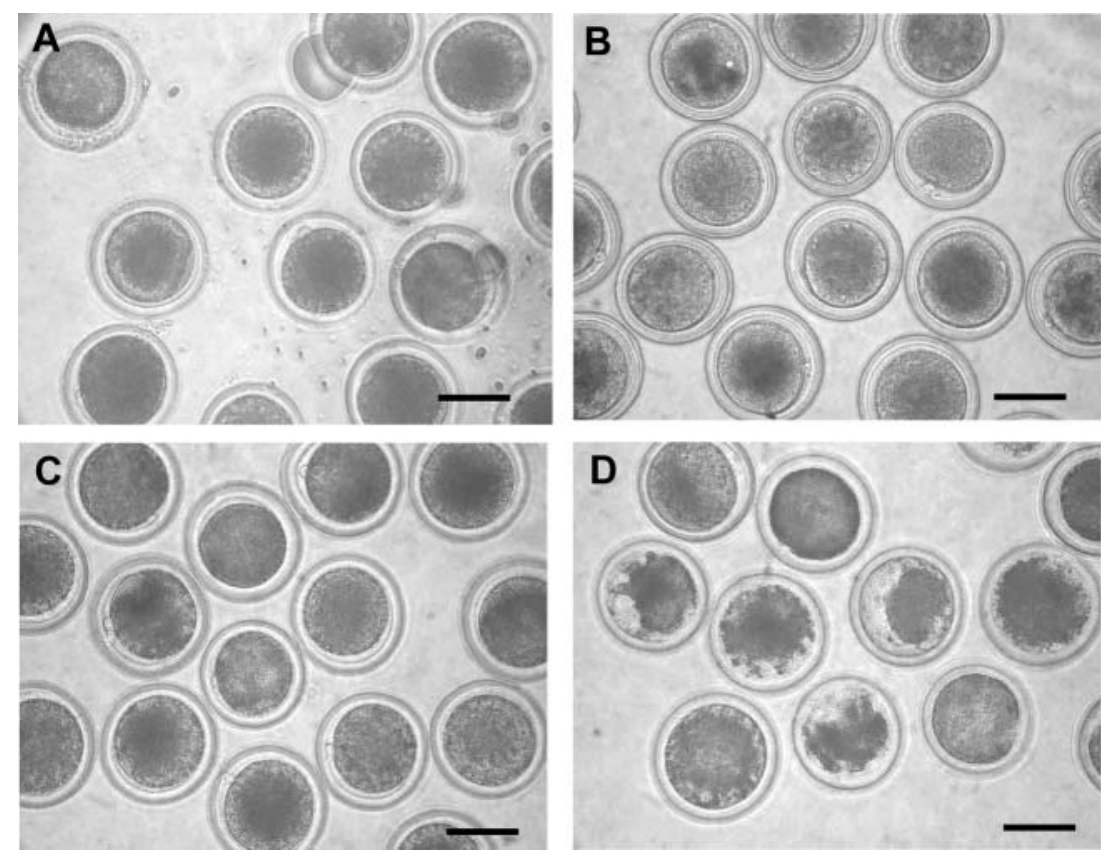

Fig. 1. Representative photographs for post-warm morphology of bovine oocytes (A: 40\% EG, B: 31\% EG, C: 28\% EG, D: 25\% EG; Scale bar $=100 \mu \mathrm{m})$.

Table 1. In vitro development of vitrified-warmed bovine oocytes after IVF and quality of blastocysts

\begin{tabular}{|c|c|c|c|c|c|c|c|c|c|}
\hline \multirow{3}{*}{$\begin{array}{c}\text { Concentration } \\
\text { of EG }\end{array}$} & \multicolumn{5}{|c|}{ No./(\%) of oocytes } & \multicolumn{4}{|c|}{ Number of cells in Day-7 blastocysts; $\bar{x} \pm S D$} \\
\hline & \multirow{2}{*}{ Vitrified } & \multirow[b]{2}{*}{ Survived* } & \multirow{2}{*}{ Cleaved } & \multicolumn{2}{|c|}{ Developed to blastocysts until } & \multirow[b]{2}{*}{$\mathrm{N}$} & \multirow[b]{2}{*}{ Total } & \multirow[b]{2}{*}{ ICM cells } & \multirow[b]{2}{*}{$(\% \mathrm{ICM})$} \\
\hline & & & & Day-7 & Day-8 & & & & \\
\hline $40 \% \mathrm{EG}$ & 175 & $157(90)^{\mathrm{a}}$ & $78(50)^{\mathrm{a}}$ & $12(7)^{b}$ & $16(10)^{\mathrm{b}}$ & 12 & $51.4 \pm 27.0^{\mathrm{b}}$ & $10.8 \pm 8.9^{\mathrm{b}}$ & $(18.2 \pm 8.2)^{\mathrm{c}}$ \\
\hline $31 \%$ EG & 160 & $144(90)^{\mathrm{a}}$ & $70(49)^{\mathrm{a}}$ & $17(12)^{\mathrm{b}}$ & $25(17)^{\mathrm{ab}}$ & 16 & $57.9 \pm 19.3^{b}$ & $14.5 \pm 5.6^{\mathrm{b}}$ & $(24.8 \pm 5.6)^{\mathrm{abc}}$ \\
\hline $28 \% \mathrm{EG}$ & 144 & $124(86)^{\mathrm{a}}$ & $60(48)^{\mathrm{a}}$ & $13(10)^{b}$ & $15(12)^{\mathrm{ab}}$ & 9 & $60.8 \pm 16.1^{\mathrm{ab}}$ & $14.3 \pm 6.5^{b}$ & $(23.7 \pm 8.9)^{b}$ \\
\hline $25 \% \mathrm{EG}$ & 85 & $13(15)^{\mathrm{b}}$ & $5(38)^{b}$ & $0(0)$ & $1(8)^{\mathrm{b}}$ & - & - & - & $(-)$ \\
\hline Fresh control & 145 & - & $74(51)^{\mathrm{a}}$ & $40(28)^{\mathrm{a}}$ & $46(32)^{\mathrm{a}}$ & 40 & $83.4 \pm 30.9^{a}$ & $23.9 \pm 9.3^{\mathrm{a}}$ & $(28.7 \pm 6.0)^{\mathrm{a}}$ \\
\hline
\end{tabular}

${ }^{a-c}$ Different superscripts within columns denote significant differences of $\mathrm{P}<0.05$ (one-way ANOVA/Tukey's test). *Oocytes that appeared to be morphologically normal. Experiments were repeated at least four times.

difference in the percentages of ICM cells based on the total number of blastocyst cells between the groups (Table 2).

\section{Discussion}

We have previously demonstrated that gel-loading tip vitrification using VS of permeable $20 \%$ EG $+20 \%$ DMSO and non-permeable $0.6 \mathrm{M}$ sucrose, originally reported for OPS vitrification [5, 6], was effective in cryopreserving IVF-derived bovine embryos at various stages of development [14-16]. In the present study, the applicability of gel-loading tip vitrification was successfully extended to in vitro-matured and denuded bovine oocytes, especially by using a VS of $31 \%$ EG and $1.0 \mathrm{M}$ sucrose following a gentle pre-equilibration treatment with 3\% EG for 8-15 min. The blastocyst yield 8 days after IVF of vitrified-warmed oocytes (17\%) was not significantly different from that of fresh control oocytes (32\%), as shown in Table 1 (Experiment 1 ). Loss of oocyte viability after vitrification in suboptimal concentrations of EG is probably due to chemical toxicity of the VS when the EG concentration is too high, mechanical damage caused by unstable glass-like solidification during cooling, and/or devitrification during warming when the EG concentration is too low. In our 

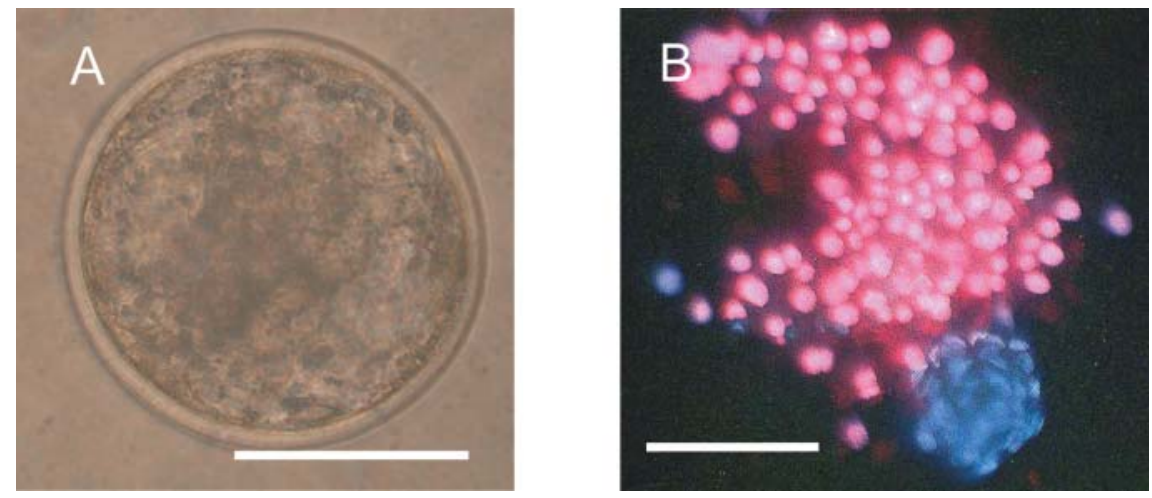

Fig. 2. A Day-7 bovine blastocyst derived from IVF of vitrified oocytes (A) and its differential cell staining $(B$; Blue $=$ ICM cells, Red $=$ trophectoderm cells $)$. Scale bar $=100 \mu \mathrm{m}$.

Table 2. Successful use of vitrified-warmed bovine oocytes for somatic cell nuclear transplantation

\begin{tabular}{|c|c|c|c|c|c|c|c|c|c|c|}
\hline \multirow[t]{3}{*}{ Groups } & \multicolumn{6}{|c|}{ No./(\%) of couplets } & \multicolumn{4}{|c|}{ Number of cells in Day-7 blastocysts; $\overline{\mathrm{x}} \pm \mathrm{SD}$} \\
\hline & \multirow[b]{2}{*}{ Prepared } & \multirow[b]{2}{*}{ Fused } & \multirow[b]{2}{*}{ Cleaved } & \multicolumn{3}{|c|}{ Developed to blastocysts until } & \multirow[b]{2}{*}{$\mathrm{N}$} & \multirow[b]{2}{*}{ Total } & \multirow{2}{*}{ ICM cells } & \multirow[b]{2}{*}{$(\% \mathrm{ICM})$} \\
\hline & & & & Day-6 & Day-7 & Day-8 & & & & \\
\hline Vitrified & 85 & $67(79)$ & $47(70)$ & $10(15)^{b}$ & $22(33)^{b}$ & $30(45)$ & 21 & $71.6 \pm 30.4^{b}$ & $17.4 \pm 7.5^{b}$ & $(23.8 \pm 0.5)$ \\
\hline Fresh control & 89 & $64(72)$ & $46(72)$ & $18(28)^{\mathrm{a}}$ & $33(52)^{\mathrm{a}}$ & $37(58)$ & 33 & $93.0 \pm 26.3^{\mathrm{a}}$ & $22.1 \pm 7.5^{\mathrm{a}}$ & $(23.7 \pm 0.5)$ \\
\hline
\end{tabular}

$\overline{\mathrm{a}, \mathrm{b}}$ Different superscripts within columns denote significant differences of $\mathrm{P}<0.05$ (one-way ANOVA). Experiments were repeated at least four times.

preliminary experiment using a VS containing $20 \%$ EG $+20 \%$ DMSO $+0.6 \mathrm{M}$ sucrose, only $10 \%$ of 112 bovine oocytes vitrified in gel-loading tips developed into blastocysts within 8 days of IVF (data not shown). This modification of the design of VS composition was derived from a report on micro-droplet vitrification by Papis et al. [10] in which $30 \%$ of vitrified bovine oocytes developed into blastocysts 8 days after IVF without a significant difference, $42 \%$ for fresh control oocytes. Other "ultra-rapid" vitrification method for cryopreserving in vitro-matured bovine oocytes resulted in blastocyst yields after IVF of $15 \%$ for electron microscope grid vitrification (vs. $42 \%$ for fresh control) [4], $25 \%$ for OPS vitrification (vs. $48 \%$ for fresh controls; in this case, COCs were denuded $6 \mathrm{~h}$ after onset of maturation culture) [5], and $19 \%$ for solid surface vitrification (vs. 33\% for fresh controls) [11], all of which were better than $<5 \%$ for the conventional two-step freezing method $[1,2]$ and $3-10 \%$ for the $0.25-\mathrm{mL}$ straw vitrification method [20,21]. Direct comparison of OPS vs. solid surface vitrification for cryoreservation of Chinese-native bovine oocytes [22] resulted in yields of Day-8 blastocysts of 13 vs. $6 \%$, respectively, under experiment conditions in which $23 \%$ of fresh control oocytes developed into blastocysts.

In the present study (Experiment 2), bovine mature oocytes vitrified in a VS of $31 \% \mathrm{EG}+1.0 \mathrm{M}$ sucrose were enucleated without a reduction in the success rate (88 vs. $93 \%$ in fresh control). This is in agreement with previous reports in which successful enucleation rates for fresh vs. vitrified bovine oocytes did not differ (87 vs. $91 \%$ [11]; 66 vs. $71 \%$ [23], respectively), but is not in agreement with the results of Kubota et al. [3], who reported a lower success rate for enucleation in frozen vs. fresh bovine oocytes (61 vs. $83 \%$, respectively). In a SCNT experiment using buffalo mature oocytes after cryotop vitrification [24], we have reported similar enucleation rates for fresh vs. vitrified oocytes (96 vs. $88 \%$, respectively). A short-term culture prior to IVF (2$3 \mathrm{~h}$ ) and SCNT (1 h) was employed for post-warm bovine oocytes in the present study, since the abnormal spindle structure reported in frozen-thawed bovine oocytes [25] may be repaired by a 2-h incubation prior to IVF $[26,27]$. Although a recent study by Chian et al. [28] indicated that bovine mature oocytes cryopreserved by vitrification in a VS containing $E G$ and $P R O H$ using a 
plastic sticker (the device improved cryotop for large quantities of oocytes) did not require such an incubation time prior to the IVF, it is suggested that sufficient restoration of the integrity of the microtubule organization after incubation in EG-based vitrification is required to enhance the outcome of fertilization and SCNT for vitrified oocytes [29]. Here, we report a yield of bovine SCNT blastocysts from vitrified-warmed oocytes as high as $45 \%$, statistically comparable with $58 \%$ in the fresh control group on Day-8 (Table 2). Dinnyes et al. [11] reported that there was no significant difference in production efficiency of bovine SCNT blastocysts between vitrified and fresh control oocytes on Day-8 (21 and 28\%, respectively) and Day-9 (27 and $29 \%$, respectively). Atabay et al. [23] also reported that $24 \%$ of bovine oocytes after solid-surface vitrification developed into SCNT blastocysts on Day-7, which was comparable with $33 \%$ of fresh control oocytes.

Regarding the qualitative aspects of IVF- or SCNTderived bovine blastocysts, the developmental rate and cell numbers of the blastocysts have been used as practical alternatives to confirmation of pregnancy or birth of calves, while the birth of calves is undoubtedly the most rigorous criterion for determining the true viability of embryos. In the present study, both Day-7 IVF and SCNT blastocysts derived from vitrified oocytes were composed of a smaller number of ICM and trophectoderm cells than the corresponding fresh Day-7 blastocysts, while the percentages of ICM cells based on the total number of blastocyst cells were comparable with the percentages of fresh control blastocysts. These results indicate a slower developmental rate for SCNT blastocysts derived from vitrified oocytes. Atabay et al. [23] reported that the total number of cells in bovine SCNT blastocysts derived from vitrified oocytes was smaller than that in fresh oocytes (116.8 vs. 175.3, respectively). Dinnyes et al. also demonstrated that development to the blastocyst stage after SCNT derived from vitrified oocytes was slower than for fresh oocytes. Based on these results, when embryo quality is compared between IVF- and SCNTderived blastocysts, the adverse effect of vitrification seems to be more detectable in IVF-derived blastocysts, suggesting that the nucleus (maternal chromosomes) and surrounding cytoplasm (microtubules of meiotic spindles) are sensitive to cryopreservation [30]. Both decreasing temperature [31] and the DMSO itself [32] induce depolymerization of spindle microtubules and abnormal aster formation, both at the spindle poles and in the cytoplasm. Therefore, gel-loading tip vitrification using a VS with a lower concentration of EG is basically effective in allowing rapid passage through the "dangerous" temperature zone for the spindle depolymerization and in minimizing the chemical and osmotic toxicity of the VS.

In conclusion, bovine oocytes cryopreserved by vitrification using a gel-loading tip were capable of developing into blastocysts after conventional IVF and SCNT. The quality of the resultant blastocysts, judged by developmental kinetics and total/ICM cell numbers, was not completely equal to that of control blastocysts, but overall yields of IVF and SCNT blastocysts derived from vitrified oocytes were comparable to those from fresh oocytes.

\section{Acknowledgments}

We would like to thank the stuffs of the Hyogo Meat Inspection Center for their great cooperation in providing bovine ovaries.

\section{References}

1) Fuku, E., Kojima, T., Shioya, Y., Marcus, G.J. and Downey, B.R. (1992): In vitro fertilization and development of frozen-thawed bovine oocytes. Cryobiology, 29, 485-492.

2) Otoi, T., Tachikawa, S., Kondo, S. and Suzuki, T. (1993): Developmental capacity of bovine oocytes frozen in different cryoprotectants. Theriogenology, 40, 801-807.

3) Kubota, C., Yang, X., Dinnyes, A., Todoroki, J., Yamakuchi, H. and Mizoshita, K. (1998): In vitro and in vivo survival of froze-thawed bovine oocytes after IVF, nuclear transfer and parthenogenetic activation. Mol. Reprod. Dev., 51, 281-286.

4) Martino, A., Songsasen, N. and Leibo, S.P. (1996): Development into blastocysts of oocytes cryopreserved by ultra-rapid cooling. Biol. Reprod., 54, 1059-1069.

5) Vajta, G., Holm, P., Kuwayama, M., Booth, P.J., Jacobsen, H., Greve, T. and Callesen, H. (1998): Open Pulled Straw (OPS) vitrification: a new way to reduce cryoinjuries of bovine ova and embryos. Mol. Reprod. Dev., 51, 53-58.

6) Vajta, G., Lewis, L., Kuwayama, M., Greave, M.T. and Callesen, H. (1998): Sterile application of the open pulled straw (OPS) vitrification method. Cryo-Lett., 19, 389-392.

7) Lane, M., Bavister, B.D., Lyons, E.A. and Forest, K.T. (1999): Containerless vitrification of mammalian oocytes and embryos: Adapting a proven method for flash-cooling protein crystals to the cryopreservation of live cells. Nat. Biotechnol., 17, 1234-1236.

8) Kuwayama, M. and Kato, O. (2000): All-round vitrification method for human oocytes and embryos. J. Assist. Reprod. Genet., 17, 477 (abstr.).

9) Laowtammathron, C., Lorthongpanich, C., Ketudat-Cairns, 
M., Hochi, S. and Parnpai, R. (2005): Factors affecting cryosurvival of nuclear-transferred bovine and swamp buffalo blastocysts: effects of hatching stage, linoleic acidalbumin in IVC medium and Ficoll supplementation to vitrification solution. Theriogenology, 64, (in press).

10) Papis, K., Shimizu, M. and Izaike, Y. (2000): Factors affecting the survivability of bovine oocytes vitrified in droplets. Theriogenology, 54, 651-658.

11) Dinnyes, A., Dai, Y., Jiang, S. and Yang, X. (2000): High developmental rates of vitrified bovine oocytes following parthenogenetic activation, in vitro fertilization, and somatic cell nuclear transfer. Biol. Reprod., 63, 513-518.

12) Hochi, S., Akiyama, M., Minagawa, G., Kimura, K. and Hanada, A. (2001): Effects of cooling and warming rates during vitrification on fertilization of in vitro-matured bovine oocytes. Cryobiology, 42, 69-73.

13) Matsumoto, H., Jiang, J.Y., Tanaka, T., Sasada, H. and Sato, E. (2001): Vitrification of large quantities of immature bovine oocytes using nylon mesh. Cryobiology, 42, 139-144.

14) Tominaga, K. and Hamada, Y. (2001): Gel-loading tip as container for vitrification of in vitro-produced bovine embryos. J. Reprod. Dev., 47, 267-273.

15) Tominaga, K. and Hamada, Y. (2004): Efficient production of sex-identified and cryopreserved bovine in-vitro produced blastocysts. Theriogenology, 61, 1181-1191.

16) Tominaga, K., Shimizu, M., Ooyama, S. and Izaike, Y. (2000): Effect of lipid polarization by centrifugation at different developmental stages on post-thaw survival of bovine in vitro produced 16-cell embryos. Theriogenology, 53, 1669-1680.

17) Brackett, B.G. and Oliphant, G. (1975): Capacitation of rabbit spermatozoa in vitro. Biol. Reprod., 12, 260-274.

18) Rosenkrans, C.F.J., Zeng, G.Q., MCNamara, G.T., Schoff, P.K. and First, N.L. (1993): Development of bovine embryos in vitro as affected by energy substrates. Biol. Reprod., 49, 459-462.

19) Akagi, S., Takahashi, S., Adachi, N., Hasegawa, K., Sugawara, T., Tozuka, Y., Yamamoto, E., Shimizu, M. and Izaike, Y. (2003): In vitro and in vivo developmental potential of nuclear transfer embryos using bovine cumulus cells prepared in four different conditions. Cloning Stem. Cells, 5, 101-108.

20) Hamano, S., Koikeda, A., Kuwayama, M. and Nagai, T. (1992): Full-term development of in vitro-matured, vitrified and fertilized bovine oocytes. Theriogenology, 38, 1085-1090.

21) Otoi, T., Yamamoto, K., Koyama, N., Tachikawa, S. and
Suzuki, T. (1998): Cryopreservation of mature bovine oocytes by vitrification in straws. Cryobiology, 37, 77-85.

22) Li, X., Su, L., Li, Y., Ji, W. and Dinnyes, A. (2002): Vitrification of Yunnan yellow cattle oocytes: work in progress. Theriogenology, 58, 1253-1260.

23) Atabay, E.C., Takahashi, Y., Katagiri, S., Nagano, M., Koga, A. and Kanai, Y. (2004): Vitrification of bovine oocytes and its application to intergeneric somatic cell nucleus transfer. Theriogenology, 61, 15-23.

24) Parnpai, R., Laowtammathron, C., Terao, T., Lorthongpanich, C., Muenthaisong, S., Vtchayan, T. and Hochi, S. (2004): Development into blastocysts of swamp buffalo oocytes after vitrification and nuclear transfer. Reprod. Fertil. Develop., 16, 180-181 (abstr.)

25) Aigner, S., Van der Elst, J., Siebzehrubl, E., Wildt, L., Lang, N. and Van Steirteghem, A.C. (1992): The influence of slow and ultra-rapid freezing on the organization of the meiotic spindle of the mouse oocyte. Hum. Reprod., 7, 857-864.

26) Im, K., Kang, J.K. and Kim, H.S. (1997): Effects of cumulus cells, different cryoprotectants, various maturation stages and preincubation before insemination on developmental capacity of frozen-thawed bovine oocytes. Theriogenology, 47, 881-891.

27) Asada, M. and Fukui, Y. (2000): Effect on fertilization and development by re-culture after freezing and thawing of bovine oocytes matured in vitro. Theriogenology, 54, 889898.

28) Chian, R.C., Kuwayama, M., Tan, L., Tan, J., Kato, O. and Nagai, T. (2004): High survival rate of bovine oocytes matured in vitro following vitrification. J. Reprod. Dev., 50, 685-696.

29) Chen, S.U., Lien, Y.R., Cheng, Y.Y., Chen, H.F., Ho, H.N. and Yang, Y.S. (2001): Vitrification of mouse oocytes using closed pulled straws (CPS) achieves a high survival and preserves good patterns of meiotic spindles, compared with conventional straws, open pulled straws (OPS) and grids. Hum. Reprod., 16, 2350-2356.

30) Moor, R. and Crosby, I. (1985): Temperature-induced abnormalities in sheep oocytes during maturation. J. Reprod. Fertil., 75, 467-473.

31) Aman, R.R. and Parks, J.E. (1994): Effects of cooling and rewarming on the meiotic spindle and chromosomes of in vitro-matured bovine oocytes. Biol. Reprod., 50, 103-110.

32) Johnson, M.H. and Pickering, S.J. (1987): Effects of dimethylsulphoxide on the microtubular system of the mouse oocyte. Development, 100, 313-324. 